\title{
PERCEPTIONS OF DENTAL STRESS AND SOCIAL SUPPORT AMONG MALAYSIAN DENTAL STUDENTS
}

R. Saub, S.M. Rajesh, V. Muirhead, T.N. Mohd Dom, N.M.

Ismail, M. Jamaludin. Perceptions of Dental Stress and Social Support among Malaysian Dental students. Annal Dent Univ Malaya 2013; 20(1): 1-7

\begin{abstract}
Objective: To explore the association between social support and stress levels in preclinical and clinical dental students in Malaysia. Method: A cross sectional survey of dental undergraduate students was conducted at the Faculty of Dentistry, University of Malaya, Universiti Kebangsaan Malaysia and Universiti Sains Malaysia. Stress was measured using the Dental Environment Stress (DES) questionnaire. A DES-32 item was used to measure stress for the clinical students and DES-16 item for the preclinical students. Four questions were used to measure social support. The total stress scores were standardized for comparison purposes. Results: A total of 357 (79.7\%) preclinical and $417(71.8 \%)$ clinical undergraduate dental students responded to the questionnaires. The clinical students experienced higher stress [mean standardized DES score $=72.63, \mathrm{SD}=10.64]$ than preclinical students [mean standardized DES score $=70.19, \mathrm{SD}=12.01]$. The two most stressful items reported by preclinical students were "fear of failing" and "examination and grades". Among clinical students, the two most stressful items related to academic were "completing course requirement" and "fear of failing course" and items related to clinical session were "fear of being barred due to the clinical schedule" and "patients late or absent". Multiple regression analyses revealed that low stress levels among preclinical students were significantly associated to a lot of contact with students of the same course. Conclusion: To some extent, social support does play a role in explaining differences in perceived stress, in particular among preclinical students.
\end{abstract}

Keywords

Dental students; Stress; Stressors; Social support.

\section{INTRODUCTION}

Dental schools are deemed to be highly demanding and have stressful learning environments $(1,2)$. Several studies conducted in different parts of the world found that dental students experienced significant levels of stress throughout their training. The clinical years are perceived to be more stressful than the preclinical years due to such

\section{Original Article}

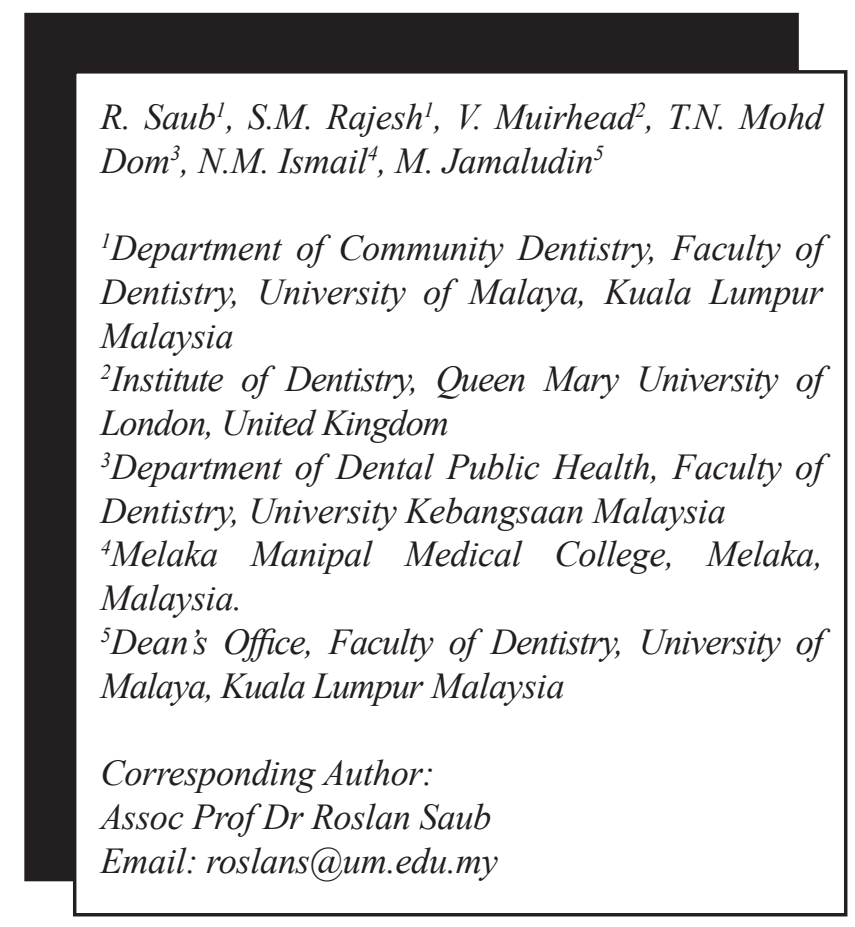

issues like dealing with patients, dental staff and academic pressures all at the same time $(3,4,5,6)$

Stress is described as external demands on the individual's physical and psychological well being (7). These external demands are known as stressors. Many studies have been conducted to identify these stressors which are related to the learning environment in dental schools. The most common stressors reported among the dental students, both preclinical and clinical students, were the 'fear of failing' and 'examination and grades' $(2$, $7,8,9,10)$

A substantial research has been done in many countries on the effects of stress either related to academic $(2,7,8,9,10,11)$ or non-academic factors such as marital status, living arrangements $(11,12)$ and its consequences to medical, social and psychological disorders $(4,9,12)$. On the contrary, there are relatively limited studies especially in the South East Asia region, where the culture is different from that of Western countries, that have investigated the effects of social support on buffering stress among dental students $(13,14)$. In this aspect, social support from friends and family has been suggested to improve individuals' well-being and academic performance by reducing anxiety and distress, especially for first year undergraduates (15). The notion of social support is perceived to have a good influence on health and it is defined as "a process through 
which the social relationships promote health and well being" (16). In addition, the concept of social support can be divided into five dimensions: structural aspects of social support networks (for e.g. size of person's social networks), functional aspects of social support (e.g. emotional support - can be verbal or non-verbal communication of concern in order to reduce stress), enacted support (reassurance or advice in times of distress), informational support (the provision of information to guide or advice) and instrumental support (the provision of material goods, transportation, money or physical assistance) (16).

The purpose of this paper is to explore the hypothesis that social support from friends, teachers, and family helps to buffer stress among undergraduate dental students. The findings of this study can be used by dental educational institutions to identify sources of social support which may help to reduce stress among dental students. This in turn will help to create a conducive learning environment beneficial to Malaysian dental undergraduates.

\section{METHODS}

A cross-sectional survey was conducted on 774 undergraduate students enrolled in the dental schools of University of Malaya (UM), Universiti Kebangsaan Malaysia (UKM) and Universiti Sains Malaysia (USM). All three dental schools have a five-year curriculum divided into preclinical and clinical years. The first and second years in UM and UKM are the preclinical years, and third to fifth years are the clinical years. However, in USM, the preclinical years are from year one to year three, and year 4 and 5 are the clinical years.

The questionnaires were administered in early semester 1 . The survey data was collected in the context of classroom. The purpose of the research was first explained to the students while in their respective classes, prior to their lectures, and they anonymously completed the study questionnaire given to them in a sealed envelope. The participation of the students was voluntary. The investigator, however, was not present at the time of completion of the questionnaire and did not have any knowledge of the participants. The investigator used the collective participant recruitment approach and returned to subsequent classes to ensure that students who were not present at the time of distribution were given ample opportunity to participate.

The scholastic stress was measured using the Dental Environmental Scale (DES) questionnaire (17). The 16 items of DES, which excluded questions related to clinical practice were used for the preclinical students. A modified 32 item DES was used for clinical students, which was divided into academic and clinical related stressors. The DES questionnaire for both preclinical and clinical students was modified for the Malaysian students. The item pertaining to male attitudes towards female students in the original questionnaire was removed from both the questionnaires to avoid gender bias. The questionnaire was further modified for Malaysian students where questions of marital status, parenting and playing dual roles at this age which are uncommon in Malaysia have been removed. A four point Likert scale response ranging from 1 (not stressful), 2 (slightly stressful), 3 (moderately stressful) to 4 (very stressful) was used. A composite score was computed for both the 16 items and 32 items. Scores ranged from 16 to 64 for the DES-16 items scales, and 32 to 128 for the DES-32 items scales. For comparison purposes, the scores were standardized using a scale of 0 to 100. A high score indicates a higher level of stress.

Social support was measured using 4 questions: good contact with teachers, close contact with parents, lots of contact with students of the same course in the university and lots of contact with students outside the university (14). It was measured using a four point Likert scale with responses ranging from 1 (not true at all), 2 (not quite true), 3 (fairly true) to 4 (totally true). Demographic data collected were age, gender, marital status, entrance qualification and accommodation type. In Malaysia, the entry qualification to dental schools is the foundation certificate, which can be either A levels, Matriculation or High School Certificate. Accommodation arrangement for the dental students include staying with friends either in colleges or renting outside the campus or stay alone or stay with parents or other relatives.

Data were analyzed using SPSS package version 12 (SPSS Inc. Chicago, II). Reliability of the DES questionnaire was analyzed using Cronbach's Alpha. The DES -32 items and DES-16 items have excellent internal consistency (both versions Cronbach's alpha $=0.92$ ).

Frequency distributions of age, gender, marital status, entry qualification and accommodation type for preclinical and clinical students were calculated. Mean values and standard deviations were calculated for each stressor.

Simple linear regression analyses were performed using standardized stress scores of preclinical and clinical students as separate dependant variables, respectively. Independant variables were the demographic variables (university, age, gender, marital status and accommodation) and the variables of social support (lots of contact with students during the course, lots of contact with students outside the course, good contact with teachers and close contact with parents). A significance level of $\alpha=0.05$ was set.

Multiple regression analysis was conducted both for preclinical and clinical students separately with the use of stepwise methods. The variables that showed significant relationship in the bivariate analysis were included in the multiple regression analysis. 
This study was approved by the Medical Ethics Committee of the University of Malaya [DF CO0502/0011 (L)].

\section{RESULTS}

A total of 357 out of $448(79.7 \%)$ preclinical [mean age 21 yrs, SD. (0.9)] and 417 out of $581(71.8 \%)$ clinical

Table 1. Sample characteristics by Stage of Study

\begin{tabular}{|c|c|c|}
\hline \multirow[b]{2}{*}{ Characteristics } & \multicolumn{2}{|c|}{ Stage of Study } \\
\hline & $\begin{array}{c}\text { Preclinical } \\
\text { n (\%) }\end{array}$ & $\begin{array}{c}\text { Clinical } \\
\text { n (\%) }\end{array}$ \\
\hline \multicolumn{3}{|l|}{ Gender } \\
\hline Male & $86(24.9)$ & $76(18.2)$ \\
\hline Female & $268(75.1)$ & $341(81.8)$ \\
\hline \multicolumn{3}{|l|}{ Entry Qualification } \\
\hline A Levels & $1(0.3)$ & $2(0.2)$ \\
\hline Matriculation & $309(86.5)$ & $304(72.9)$ \\
\hline STPM & $47(13.2)$ & $111(26.6)$ \\
\hline \multicolumn{3}{|l|}{ Marital Status } \\
\hline Single & $296(82.9)$ & $272(65.2)$ \\
\hline Married & - & $12(2.9)$ \\
\hline Separated / divorced & - & $1(0.2)$ \\
\hline Widowed & $1(0.3)$ & $4(1.0)$ \\
\hline In a relationship & $58(16.2)$ & $121(29.0)$ \\
\hline Engaged & $2(0.6)$ & $7(1.7)$ \\
\hline \multicolumn{3}{|l|}{ Accommodation } \\
\hline Room mate/friends & $309(86.6)$ & $303(73.0)$ \\
\hline Parents & $17(4.8)$ & $33(8.0)$ \\
\hline Alone & $30(8.4)$ & $63(15.2)$ \\
\hline Other family members & $1(0.3)$ & $3(0.7)$ \\
\hline \multicolumn{3}{|l|}{ University } \\
\hline UM & $132(48.0)$ & $143(52.0)$ \\
\hline UKM & $97(32.8)$ & $199(67.2)$ \\
\hline USM & $128(63.1)$ & $75(36.9)$ \\
\hline
\end{tabular}

students [mean age $24 \mathrm{yrs}$, SD (1.1)] responded to the questionnaires. Three-fourths of the preclinical and clinical students were female. Most of the respondents were single; had matriculation (foundation studies) qualification and lived with roommates or friends (Table 1).

The clinical students [mean standardized DES score $=72.63, \mathrm{SD}=10.64]$ had significantly higher standardized stress score compared to the preclinical students [mean standardized DES score $=70.19, \mathrm{SD}=12.01]$. (Figure 1). There were 6 items out of 16 with the mean score of 3 or more for the preclinical students. The two most stressful items were "fear of failing" and "examination and grades". Clinical students had 12 out of 32 items with the mean score of three or more. Items with the mean score of 3 and above were "completing course requirement", "fear of failing course", "fear of being barred from sitting examination", "examination and grades", and "patients late or absent" (Table 2).

Simple linear regression showed that in the preclinical students, standardized stress scores reduced with

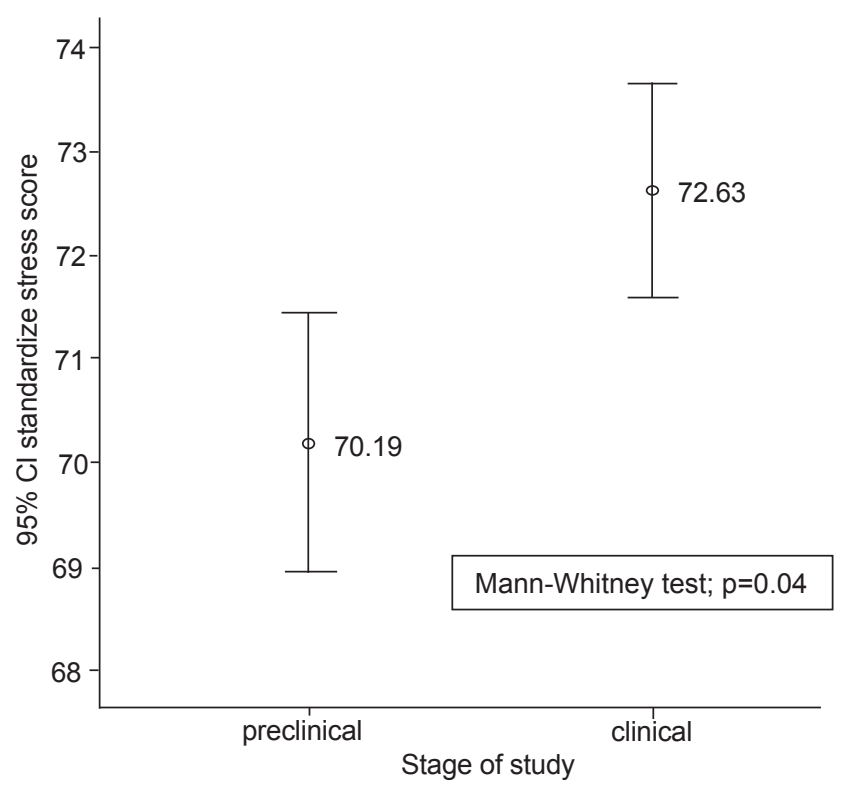

Figure 1. Standardized stress scores by Stage of Study

social support from "lots of contact with students of the same course", "lots of contact with students outside the course", "good contact with teachers". (Table 3). However, none of the social support variables seemed to be significantly associated with standardized stress score in clinical students.

The multiple linear regression model showed that "university" and "lots of contact with students in the same course" were predictors of standardized stress scores among the preclinical students whereas only "university" was found to be significantly associated with the stress score among clinical students. When compared to UM, preclinical students in UKM and USM were found to have 5 points lower in their mean standardized stress score (Table 4). They also have less stress as they have more contacts with students within the same course. However, among the clinical students, only UKM students were found to have significantly less stress level as compared to UM students during their clinical years (Table 4). 
Table 2. Mean Dental Environment Scale scores by stage of study

\begin{tabular}{|c|c|c|c|c|c|}
\hline \multirow{2}{*}{ No } & \multirow{2}{*}{ Stressors } & \multicolumn{2}{|c|}{ Preclinical } & \multicolumn{2}{|c|}{ Clinical } \\
\hline & & Mean & (s.d) & Mean & (s.d) \\
\hline 1. & Completing course requirement & 3.13 & $(0.82)$ & 3.83 & $(0.42)$ \\
\hline 2. & Fear of failing course & 3.54 & $(0.72)$ & 3.67 & $(0.64)$ \\
\hline 3. & Examination and grades & 3.47 & $(0.72)$ & 3.55 & $(0.63)$ \\
\hline 4. & Course more difficult than I imagine & 3.17 & $(0.82)$ & 3.31 & $(0.78)$ \\
\hline 5. & Ensuring good marks & 3.22 & $(0.82)$ & 3.30 & $(0.76)$ \\
\hline 6. & Fear unable to catch up if behind & 3.17 & $(0.78)$ & 3.23 & $(0.78)$ \\
\hline 7. & Lack of time to do assignments & 2.72 & $(0.80)$ & 3.10 & $(0.79)$ \\
\hline 8. & Receiving criticism about work & 2.71 & $(0.81)$ & 3.08 & $(0.82)$ \\
\hline 9. & Amount of assigned class work & 2.45 & $(0.82)$ & 3.03 & $(0.82)$ \\
\hline 10. & Lack of confident successful dental student & 2.94 & $(0.87)$ & 2.98 & $(0.88)$ \\
\hline 11. & Difficulty of class work & 2.71 & $(0.82)$ & 2.97 & $(0.74)$ \\
\hline 12. & Financial problems & 2.15 & $(0.91)$ & 2.46 & $(0.94)$ \\
\hline 13. & Students breaking rules in school & 1.83 & $(0.83)$ & 2.15 & $(0.97)$ \\
\hline 14. & Personal physical health & 1.93 & $(0.86)$ & 2.07 & (0.89) \\
\hline 15. & Lack of time relaxation & 2.93 & $(0.91)$ & 2.98 & $(0.87)$ \\
\hline 16. & Lack confidence to be a successful dentist & 2.87 & $(0.88)$ & 2.83 & $(0.89)$ \\
\hline 17. & Patients late or absent & & & 3.54 & $(0.67)$ \\
\hline 18. & Inconsistencies between the instructors & & & 3.38 & $(0.72)$ \\
\hline 19. & Difficulty learning a laboratory skill & & & 2.98 & $(0.82)$ \\
\hline 20. & Fear of being barred due to the clinical schedule & & & 3.57 & $(0.72)$ \\
\hline 21. & Difficulty learning clinical skill & & & 2.90 & $(0.83)$ \\
\hline 22. & Lack of input into the decision making process & & & 2.87 & $(0.74)$ \\
\hline 23. & Atmosphere being on clinical course & & & 2.83 & $(0.87)$ \\
\hline 24. & Difficulty learning clinical procedure & & & 2.83 & $(0.78)$ \\
\hline 25. & Rules and regulations of the school & & & 2.76 & (0.93) \\
\hline 26. & Lack of co-operation of patients In their home care & & & 2.73 & $(0.80)$ \\
\hline 27. & Responsibilities for comprehensive patient care & & & 2.67 & $(0.74)$ \\
\hline 28. & Working on patients with a dirty mouth & & & 2.57 & $(0.92)$ \\
\hline 29. & Insecurity concerning professional future & & & 2.40 & (0.93) \\
\hline 30. & Lack of atmosphere in the living quarters & & & 2.30 & $(0.87)$ \\
\hline 31. & Discrimination ethnic group & & & 2.15 & $(1.00)$ \\
\hline 32. & Work while family in the house & & & 1.96 & $(0.85)$ \\
\hline
\end{tabular}

\section{DISCUSSION}

This study was done to determine the stressors and to explore the hypothesis that social support from friends, teachers and family helps to buffer stress among the undergraduate dental students in Malaysia. It was conducted in three different dental schools of Malaysia to cover a wider range of study conditions.

Examination grades, completing course requirement and fear of failing were the common stressors identified by the preclinical and clinical students and are similar to many studies done around the globe $(18,19,20)$. Despite these similarities, stressors reported among the clinical students in Malaysia were "patients late or absent" and "inconsistencies between instructors". In the present study, problems such as patients turning up late or not turning up for an appointment may reflect some cultural factors that make it difficult for inexperienced dental students to handle; being younger than their global counterparts who usually have had a basic degree prior to enrolment to the dental school, for example at the University of Toronto where the applicants to Doctor of Dental Surgery program must have completed three years of university education, and would be more matured with regard to patient management.

Stressors related to inconsistencies between instructors may be attributed to the fact that clinical instructors in Malaysia have received training from 
Table 3. Simple Linear Regression for the independent factors with standardized stress score

\begin{tabular}{|c|c|c|c|c|c|c|c|c|}
\hline \multirow{3}{*}{$\begin{array}{l}\text { Independent variables } \\
\text { Lots of contact with students } \\
\text { within course }\end{array}$} & \multicolumn{4}{|c|}{ Preclinical } & \multicolumn{4}{|c|}{ Clinical } \\
\hline & \multicolumn{2}{|c|}{$\begin{array}{c}\beta \text { coefficient } \\
(95 \% \mathrm{Cl})\end{array}$} & \multirow{2}{*}{$\begin{array}{l}\text { t-stat } \\
-3.76\end{array}$} & \multirow{2}{*}{$\begin{array}{c}\text { p-value } \\
0.00\end{array}$} & \multicolumn{2}{|c|}{$\begin{array}{c}\beta \text { coefficient } \\
(95 \% \mathrm{Cl})\end{array}$} & \multirow{2}{*}{$\begin{array}{l}\text { t-stat } \\
-0.36\end{array}$} & \multirow{2}{*}{$\begin{array}{r}\text { p-value } \\
0.72\end{array}$} \\
\hline & -5.09 & $(-7.75,-2.43)$ & & & -2.55 & $(-1.64,1.13)$ & & \\
\hline $\begin{array}{l}\text { Lot of contact with students } \\
\text { outside the course }\end{array}$ & -2.75 & $(-5.17,-3.25)$ & -2.23 & 0.03 & 0.81 & $(-0.36,1.98)$ & 1.36 & 0.18 \\
\hline Good contact with teachers & -3.2 & $(-5.43,-1.06)$ & -2.93 & 0.01 & -0.46 & $(-2.01,1.09)$ & -0.59 & 0.56 \\
\hline Close contact with parents & -2.73 & $(-6.32,0.86)$ & -1.49 & 0.14 & 0.22 & $(-1.37,1.81)$ & 0.27 & 0.79 \\
\hline Age & -0.19 & $(-1.47,1.10)$ & -0.29 & 0.77 & -0.03 & $(-0.91,0.85)$ & -0.06 & 0.95 \\
\hline \multicolumn{9}{|l|}{ Gender } \\
\hline Male & - & - & - & - & - & - & - & - \\
\hline Female & -0.65 & $(-3.54,2.24)$ & -0.44 & 0.66 & 1.24 & $(-1.43,3.90)$ & 0.91 & 0.36 \\
\hline \multicolumn{9}{|l|}{ University } \\
\hline UM & - & - & - & - & - & - & - & - \\
\hline UKM & -2.73 & $(-5.53,0.07)$ & -1.92 & 0.06 & -3.02 & $(-5.05,-0.98)$ & -2.92 & 0.04 \\
\hline USM & -3.26 & $(-5.85,-0.67)$ & -2.47 & 0.02 & 2.47 & $(-0.19,5.13)$ & 1.83 & 0.07 \\
\hline \multicolumn{9}{|l|}{ Marital status } \\
\hline Single & - & - & - & - & - & - & - & - \\
\hline Married & -4.58 & $(-28.27,19.10)$ & -0.38 & 0.70 & 0.32 & $(-4.87,5.50)$ & 0.12 & 0.90 \\
\hline \multicolumn{9}{|l|}{ Accommodation } \\
\hline Friends & - & - & - & - & - & - & - & - \\
\hline Parents & 2.05 & $(-3.82,7.93)$ & 0.69 & 0.49 & -0.28 & $(-4.09,3.52)$ & -0.15 & 0.88 \\
\hline Alone & -2.20 & $(-6.71,2.31)$ & -0.96 & 0.34 & -1.89 & $(-4.75,0.93)$ & -1.30 & 0.19 \\
\hline Others & -10.85 & $(-34.51,12.81)$ & -0.90 & 0.37 & 0.49 & $(-5.92,6.89)$ & 0.15 & 0.88 \\
\hline
\end{tabular}

Dependent variable: Standardized stress scores

Table 4. Association between predictor variables with standardized stress scores in each stage of Study using multiple linear regression analysis

\begin{tabular}{|c|c|c|c|}
\hline Predictors & Adjusted $\beta(95 \% \mathrm{Cl})$ & t- stat & P-value \\
\hline \multicolumn{4}{|l|}{ Preclinical } \\
\hline Constant & $82.32(77.18,87.46)$ & 31.48 & $<0.001$ \\
\hline \multicolumn{4}{|l|}{ University } \\
\hline UM & - & - & - \\
\hline UKM & $-5.05(-8.09,-2.00)$ & -3.26 & 0.001 \\
\hline USM & $-5.40(-8.22,-2.58)$ & -3.77 & $<0.001$ \\
\hline $\begin{array}{l}\text { Lots of contact with students within } \\
\text { courses }\end{array}$ & $-2.99(-4.63,-1.35)$ & -3.57 & $<0.001$ \\
\hline \multicolumn{4}{|l|}{ Clinical } \\
\hline Constant & $74.07(72.66,75.47)$ & 103.5 & $<0.001$ \\
\hline \multicolumn{4}{|l|}{ University } \\
\hline UM & - & - & - \\
\hline UKM & $-3.02(-5.05,-0.98)$ & -2.91 & 0.004 \\
\hline USM & $0.62(-2.33-6.59)$ & 0.42 & 0.677 \\
\hline
\end{tabular}

$\mathrm{R}^{2}$ for preclinical model $=8 \%$

$\mathrm{R}^{2}$ for clinical model $=2 \%$ 
different parts of the world and inadvertently have varied approaches to patient management. In addition, clinical students have to complete a clinical schedule before they are allowed to sit for their professional examination. Inconsistencies between instructors could delay their completion of schedule which could contribute to stress. This situation was also observed in Toronto, Canada. To overcome this problem, the school has introduced calibration program to all its instructors (11). Perhaps, dental school in Malaysia can also follow suit.

The social support especially close contact with students of the same course, close contact with students outside the course and good contact with teachers, seems to lower the stress levels among the preclinical students. The students' course mate may provide the emotional support for problems related to the study, while outside the course, friends will mainly provide the social support network for the dental students. Teachers on the other hand, will provide the enacted support as well as informational support to the students.

However, none of these social supports are required by the clinical students. Perhaps this can be attributed to the demanding curriculum along with maturity and skills of the students in the clinical years.

The results of this study confirmed some of the evidence from other international studies on decreased perception of stress due to enhanced social support from teachers and students $(14,15)$. On the other hand, this study does not reinforce the findings from a study done by Hamdan -Mansour (21) among university students in Jordan, which shows moderate reduction in stress levels due to increased social support from the family.

The multiple regression analysis showed that the demand of a university is one of the factors that will predict the stress level of the dental students. Dental faculty UM is the oldest faculty in Malaysia. Being the oldest and well established faculty UM has been the benchmark for the newer faculty and hence the expectation of the university on the students is high. Perhaps this indirectly creates a stress to the students of the UM.

Although the effect of social support on stress was not uniformly distributed among undergraduate dental students, its contribution in buffering stress should be recognized by dental institutions to improve the dental student's quality of life. As the study found lowered stress levels among preclinical dental students due to contact with students of the same course, the universities can play an important role to buffer stress with provision of comfortable rooms as a favorable environment for students to interact with each other during the work day.

This study has its own set of limitations, thus, caution must be exercised in extrapolating the results as dental students from private Malaysian universities were not included in the study. This study faces similar limitations with Muirhead's (2008) study since it was a joint collaborative project (14). Among others, this includes the crude relative social support measure used in this study, validity of single items measure of social support and the exclusion of friends outside the academic circle. In addition, the results cannot definitively conclude that positive effect of social support from parents, friends and teachers helps to reduce stress due to the study design.

In conclusion, clinical students experience a higher stress than preclinical students. Fear of failing and completing course requirement are the two major sources of perceived stress among preclinical and clinical students respectively. Social support from coursemate positively correlates with reduced stress levels among preclinical students. Thus, it is recommended that this form of support be encouraged by dental institutions to promote interaction among coursemates right up to the clinical years. Time is a real issue in clinical years. Time allowance in the busy schedule may hold the key to promote interaction. Perhaps, it is timely to reorientate formal learning time to include more self-directed sessions and allow a more relaxed approach. Students can use the time for interaction among colleagues and faculties to improve social support and reduce stress.

\section{ACKNOWLEDGMENT}

The authors would like to thank the University Malaya for financing this project grant no: FO179/2007A. We would also like to express our gratitude to Dr Sheena Kaur for editing this manuscript.

\section{REFERENCES}

1. Cardall WR, Rowan RC, Bay C. Dental education from the students' perspective: curriculum and climate. J Dent Educ 2008; 72(12): 600-609.

2. Polychronopoulou A, Divaris K. Perceived sources of stress among Greek dental students. J Dent Educ 2005; 69 (suppl 6): $687-692$.

3. Newton JT, Baghaienaini F, Goodwin SR, et al. Stress in dental school: a survey of students. Dent Update 1994; 21 (4): 162-164.

4. Tedesco LA. A psychological perspective on the dental educational experience and student performance. J Dent Educ 1986; 50: 601-605.

5. Sanders AE, Lushington K. Sources of stress for Australian dental students. J Dent Educ 1999; 63: 688-697. 
6. Heath JR, Macfarlane TV, Umar MS. Perceived sources of stress in dental students. Dent Update 1999; 26 (3): 94-100.

7. Kumar S, Dagli R J, Mathur A, Jain M, Prabu D, Kulkarni S. Perceived sources of stress amongst Indian dental students. Eur J Dent Educ 2009; 13: 39-45.

8. Al-Omari WM. Perceived sources of stress within a dental educational environment. J Contemp Dent Pract 2005; 156: 64-74.

9. Naidu RS, Adams JS, Simeon D, Persad S. Sources of stress and psychological disturbance among dental students in the West Indies. J Dent Educ 2002; 66 (9): 1021-1030.

10. Bradely IF, Clark DC, Eisner JE, et al. The student's survey of problems in the academic environment in Canadian dental faculties. J Dent Educ 1989; 53(suppl 2): 126- 131.

11. Muirhead V, Locker D. Canadian dental students' perceptions of stress. J Can Dent Assoc 2007; 73(suppl 4): 323.

12. Musser LA, Lloyd C. The relationship of marital status and living arrangement to stress among dental students. J Dent Educ 1985; 49(suppl 8): 573-578.

13. Goldstein MB. Interpersonal support and coping among first- year dental students. J Dent Educ 1980; 44(suppl 4): 202-205.

14. Muirhead V, Locker D. Canadian dental students' perceptions of stress and social support. Eur J Dent Educ 2008; 12 (3): 144-148.
16. Lawson TJ, Fuehrer A. The role of social support in moderating the stress that first - year graduate students experience. Educ 1989; 110: 186-193.

17. Normah CD, Azlin MH, Md. Idris $\mathrm{MN}$ et al. Parenting and social support as perceived by adolescents: a comparison between three Felda land scheme developments. Malay J Psych 2005; 13: 4352.

18. Humphris G, Blinkhorn A, Freeman R, Gorter R, Hoad-. Reddick G, Murtomaa H, et al. Psychological stress in undergraduate dental students: baseline results from seven European dental schools. Eur J Dent Educ 2002; 6 (1): 22-29

19. Rosli TI, Abdul Rahman R, Abdul Rahman SR, Ramli R. A survey of perceived stress among undergraduate dental students in Universiti Kebangsaan Malaysia. Singapore Dent J. 2005; 27(1):17-22.

20. Divaris K, Barlow PJ, Chendea SA, et al. The academic environment: the students' perspective. Euro J of Dent Educ 2008; 12 (Supp1.1): 120-130.

21. Alzahem AM, van der Molen HT, Alaujan AH, Schmidt HG, Zamakhshary MH. Stress amongst dental students: a systematic review. Eur J Dent Educ 2011; 15 (1):8-18.

22. Hamdan-Mansour AM, Dawani HA. Social support and stress among university students in Jordan. Int $\mathrm{J}$ Mental. Health Addiction 2008; 6: 442-450. 